\title{
Iron deficiency in heart failure patients: the French CARENFER prospective study
}

\author{
Alain Cohen-Solal ${ }^{1 *}$, Jean-Luc Philip ${ }^{2}$, François Picard ${ }^{3}$, Nicolas Delarche ${ }^{4}$, Guillaume Taldir ${ }^{5}$, Heger Gzara ${ }^{6}$, \\ Anissa Korichi ${ }^{7}$, Jean-Noel Trochu ${ }^{8}$, Patrice Cacoub ${ }^{9,10 *}$ and CARENFER Study Group \\ ${ }^{1}$ Department of Cardiology and Vascular Disease, Paris University, UMR-S 942 MASCOT, Lariboisière Hospital, Assistance Publique-Hôpitaux de Paris, 2 rue Ambroise Paré, \\ Paris, 75010, France; ${ }^{2}$ Intensive Care Unit in Cardiology, Chalon Hospital, Chalon, France; ${ }^{3}$ Cardiology Unit, Hôpital du Haut Lévêque, University Hospital of Bordeaux, \\ Bordeaux University, Pessac, France; ${ }^{4}$ Department of Cardiology, Pau Hospital, Pau, France; ${ }^{5}$ Department of Cardiology, Saint-Brieuc Hospital, Saint Brieuc, France; ${ }^{6}$ Sud \\ Francilien Hospital, Corbeil-Essonnes, France; ${ }^{7}$ Vifor Pharma, Paris la Défense, Paris, France; ${ }^{8}$ Institut du Thorax, University Hospital of Nantes, University of Nantes, CNRS, \\ INSERM, Nantes, France; ${ }^{9}$ Department of Internal Medicine and Clinical Immunology, Groupe Hospitalier Pitié-Salpêtrière, La Pitié Salpêtrière Hospital, Assistance Publique- \\ Hôpitaux de Paris, 83 Boulevard de l'Hôpital, Paris, 75651, France; and ${ }^{10}$ Inflammation-Immunopathology-Biotherapy Department (DHU i2B), UPMC Univ Paris 06, UMR \\ 7211, INSERM, UMRS 959, Sorbonne Université, Paris, F-75005, France
}

\section{Abstract}

Aims Iron deficiency (ID) is reported as one of the main co-morbidities in patients with chronic heart failure (CHF), which then influences quality of life and prognosis. The CARENFER study aimed to assess the prevalence of ID in a large panel of heart failure (HF) patients at different stages of the disease.

Methods and results This prospective cross-sectional nationwide study was conducted in 48 medical units in France in 2019. Serum ferritin concentration and transferrin saturation (TSAT) index were determined in all eligible patients with a diagnosis of HF. ID diagnosis was based on the European Society of Cardiology (ESC) 2016 guidelines. Patients were classified as having either a decompensated HF or a CHF. Left ventricular ejection fraction (LVEF) was categorized as preserved ( $\geq 50 \%$ ), mildly reduced (40-49\%), or reduced (<40\%). ID diagnosis was determined in 1661 patients, of whom 1475 could be classified as having a decompensated HF or a CHF. Patients' median age was 78 years. Decompensated HF represented $60.1 \%$ of cases. The overall prevalence of ID was 49.6\% (47.1-52.1). In CHF and decompensated HF patients, respectively, ID prevalence was $39.0 \%$ (35.1-43.1) and 58.1\% (54.7-61.4), $P<0.001$; TSAT $<20 \%$ was respectively reported in $34.7 \%$ and $70.0 \%$ of patients $(P<0.001)$. Patients with preserved LVEF were more likely to have an ID $(57.5 \%)$ compared with patients with mildly reduced $(47.4 \%)$ or reduced LVEF $(44.3 \%)(P<0.001)$.

Conclusions Iron deficiency was highly prevalent in patients with decompensated HF or CHF with preserved LVEF. ID prevalence defined by TSAT was higher than by the ESC criteria in decompensated HF patients, questioning the importance of ID definition to assess its prevalence.

Keywords Iron deficiency; Heart failure; Prevalence; Cross-sectional studies; Epidemiology; Adults

Received: 30 August 2021; Revised: 8 January 2022; Accepted: 7 February 2022

*Correspondence to: Prof. Patrice Cacoub, Department of Internal Medicine and Clinical Immunology, Groupe Hospitalier Pitié-Salpêtrière, La Pitié Salpêtrière Hospital, Assistance Publique-Hôpitaux de Paris, 83 Boulevard de l'Hôpital, 75651 Paris, Cedex 13, France. Email: patrice.cacoub@aphp.fr;

Prof. Alain Cohen-Solal, Department of Cardiology and Vascular Disease, Paris University, UMR-S 942 MASCOT, Lariboisière Hospital, Assistance Publique-Hôpitaux de Paris, 2 rue Ambroise Paré, 75010 Paris, France. Email: alain.cohen-solal@inserm.fr

See CARENFER Study Group members in Appendix A.

One-sentence summary: Half of patients with decompensated heart failure or chronic heart failure with preserved left ventricular ejection fraction suffer from iron deficiency.

\section{Introduction}

Iron loss and/or chronic inflammation predisposes patients with chronic heart failure (CHF) to develop iron deficiency (ID), in whom it is reported as one of the main noncardiovascular co-morbidities. ${ }^{1}$ Progressive ID can result in iron-deficient erythropoiesis and, eventually, ID-associated anaemia. All heart failure (HF) subtypes as described in the European Society of Cardiology (ESC) guidelines exhibit ID. ${ }^{2}$ Prevalence of ID has been found to range from $35-40 \%$ in stable ambulatory CHF patients ${ }^{3}$ to more than $60 \%$ in patients with acute decompensated heart failure (AHF)., ${ }^{4,5}$ Most 
of these studies have addressed the prevalence of ID in CHF patients or those with $\mathrm{HF}$ with reduced ejection fraction (HFrEF). Fewer data are available in AHF, HF with preserved ejection fraction (HFpEF), or HF with mildly reduced ejection fraction (HFmrEF), 6,7

Importantly, even in the absence of anaemia, ID in patients with HF is associated with clinical signs and symptoms including fatigue ${ }^{8}$ and impaired physical performance, ${ }^{9}$ all contributing to a reduced quality of life. ${ }^{10,11}$ Observational studies have shown that the presence of ID in patients with HF is also significantly associated with a worse prognosis and a higher mortality independently of anaemia.,12

Despite the demonstrable adverse effects of ID in HF patients and their reversibility under iron therapy, systematic screening and subsequent treatment of ID in HF patients with or without anaemia remain inconsistent. In 2016, and more recently in 2021, the ESC has reaffirmed the importance of detecting and treating ID in HF patients. ${ }^{2,13}$ ID definition has been updated based on both serum ferritin level and iron saturation of transferrin (TSAT) index to account for inflammation. In France, the recommendations of the National Authority for Health (Haute Autorité de Santé) are in line with those of the ESC, recommending the combined use of serum ferritin concentration and TSAT index. ${ }^{14}$ Despite these recommendations, ID remains largely under-diagnosed in France as recently shown in a cohort study of 100000 patients undergoing iron replacement therapy. $^{15}$

In this prospective multicentre study conducted in France, we aimed to assess the prevalence of ID based on the ESC guidelines in a large panel of HF patients at different stages of the disease.

\section{Materials and methods}

\section{Study sites and population}

The CARENFER study was conducted in France between May 2019 and March 2020. It is a cross-sectional, prospective, nationwide study carried out in 48 cardiology and geriatric wards, which were selected based on a voluntary basis. Based on the conservative assumption that the prevalence of ID is $75 \%$ in HF patients, ${ }^{4}$ we calculated that 1800 patients had to be recruited to estimate the overall prevalence of ID with a precision of $2 \%$, with an alpha risk of $5 \%$. This sample size allowed estimating the prevalence of ID in males and females separately with a precision of no more than $3 \%$.

All patients present in the medical unit during the study period, whether inpatient or outpatient, with a diagnosis of $\mathrm{HF}$ regardless of left ventricular ejection fraction (LVEF) were eligible. Few inclusion criteria were considered in order to limit selection bias: 18 years old or more, registration with a social security system, and signed written informed consent. Patients under guardianship or curatorship as well as pregnant or breastfeeding women were not included.

\section{Study procedures}

For all included patients, a standardized questionnaire was conducted. The following information was retrieved from the patient's medical record: patient's demographic and clinical data (age, gender, weight, and height), date and type of hospitalization (geriatric vs. cardiology ward, inpatient vs. outpatient, and traditional vs. day hospitalization), reason for admission (decompensation vs. scheduled check-up), HF characteristics [New York Heart Association (NYHA) status before current admission and LVEF before current admission], ongoing treatment for $\mathrm{HF}$ and ID, and reported co-morbidities (diabetes, hypertension, chronic kidney disease, and coronary artery disease). For patients who had a recent (i.e. within 7 days before their inclusion in the present study) determination of haemoglobin $(\mathrm{Hb})$ level, as well as serum ferritin and TSAT measurements, no additional biochemical assessment was performed at inclusion. A data quality control was performed throughout the study to ensure that individual data collection was complete and consistent with the patient's medical record and hospital registers.

In addition, in all participating medical units, a standardized questionnaire was sent to investigators in order to document general practices within the unit regarding the assessment of ID in patients with CHF or decompensated HF. The following information was collected: iron status assessment recommended (yes/no), time of assessment (before admission or at patient's admission/discharge), and iron parameters measured.

\section{Definitions}

In this study, ID and functional/absolute ID definitions were based on the 2016 ESC guidelines: absolute ID was defined as serum ferritin $<100 \mu \mathrm{g} / \mathrm{L}$, and functional ID as the combination of a serum ferritin level between 100 and $299 \mu \mathrm{g} / \mathrm{L}$ and a TSAT index $<20 \%$. Anaemia was defined according to World Health Organization guidelines as an $\mathrm{Hb}$ level of $\leq 13$ and $\leq 12 \mathrm{~g} / \mathrm{dL}$, in males and females, respectively. According to the reason for admission, patients were classified as having either a CHF or a decompensated HF corresponding to patients with acute HF or CHF with an unplanned hospitalization for decompensation. HF was classified according to LVEF as HFrEF (<40\%), HFmrEF (40-49\%), and HFpEF ( $\geq 50 \%)$. 


\section{Statistics}

Descriptive statistics included patients' demographic, main clinical characteristics, distribution of iron parameter measurements, and $\mathrm{Hb}$ level: first, in the overall study population, then according to the type of HF (decompensated vs. chronic, as defined above) and LVEF profile. Continuous variables with a Gaussian distribution are presented as mean \pm standard deviation (SD). For variables distributed in a non-Gaussian manner, the data are shown as medians with interquartile ranges (IQRs). Normality was checked by the Shapiro-Wilk statistic. Categorical data were expressed as percentages. Comparisons between variables were assessed using the $\chi^{2}$ test for categorical variables and Wilcoxon's or Kruskal's test for quantitative variables. The level of significance was set at $P<0.05$.

The prevalence of ID, absolute/functional ID, and anaemia was calculated and then analysed according to the type of HF (decompensated vs. chronic) and LVEF profile. Comparisons between variables were assessed using the $\chi^{2}$ test. Given the significant differences expected between males and females, ${ }^{16}$ secondary analyses were conducted in the two subgroups separately. The prevalence of events was estimated with the Agresti-Coull 95\% confidence interval (CI). ${ }^{17}$ Finally, the level of agreement between TSAT $<20 \%$ and ID (based on the ESC criteria) was assessed among patients with CHF and those with decompensated HF using Cohen's kappa statistic.

All statistics were performed using both SAS $^{\circledR}$ Version 9.4 and $\mathrm{R}$ ( $\mathrm{v}$ 4.1.0).

\section{Ethics}

The protocol complied with recommendations of the Declaration of Helsinki, and the International Conference on Harmonization (ICH) guidelines for good clinical practice (GCP), all applicable laws, rules, and regulations. The protocol also complied with the French laws and regulations. Ethical approval was granted by an Ethics Committee (Comité de Protection des Personnes) designated by the French Ministry of Health. All subjects provided written informed consent. ClinicalTrials.gov Identifier: NCT03924258.

\section{Results}

\section{Study population and patients' baseline characteristics}

A total of 1733 patients were included in 48 centres, with a median (IQR) of 29 (21-43) patients by centre. Seventy-two patients were excluded from the analysis because of consent withdrawal $(n=1)$, duplicate inclusion $(n=4)$, no fulfilment of inclusion criteria $(n=2)$, and absence of biological assessment ( $n=65$ ), leaving 1661 patients for the present analysis (Figure 1). Among them, 16.1\% (267/1661) were outpatients seen at a hospital consultation and $83.9 \%$ (1394/1661) were inpatients hospitalized either in a cardiology ward [78.9\% (1100/1394)] or in a geriatric ward [21.1\% (294/1394)]. The type of HF (decompensated vs. chronic) was documented in

Figure 1 Flow chart of CARENFER study. This graph displays the number (\%) of patients with a documented stage of HF (decompensated vs. chronic) as well as a documented LVEF before admission. According to the reason for admission, patients were classified as having either a chronic HF or a decompensated HF corresponding to patients with acute or chronic HF with an unplanned hospitalization for decompensation. ID refers to the number of patients who were classified as iron deficient or not based on both iron saturation of transferrin and serum ferritin level. HF, heart failure; ID, iron deficiency; LVEF, left ventricular ejection fraction.

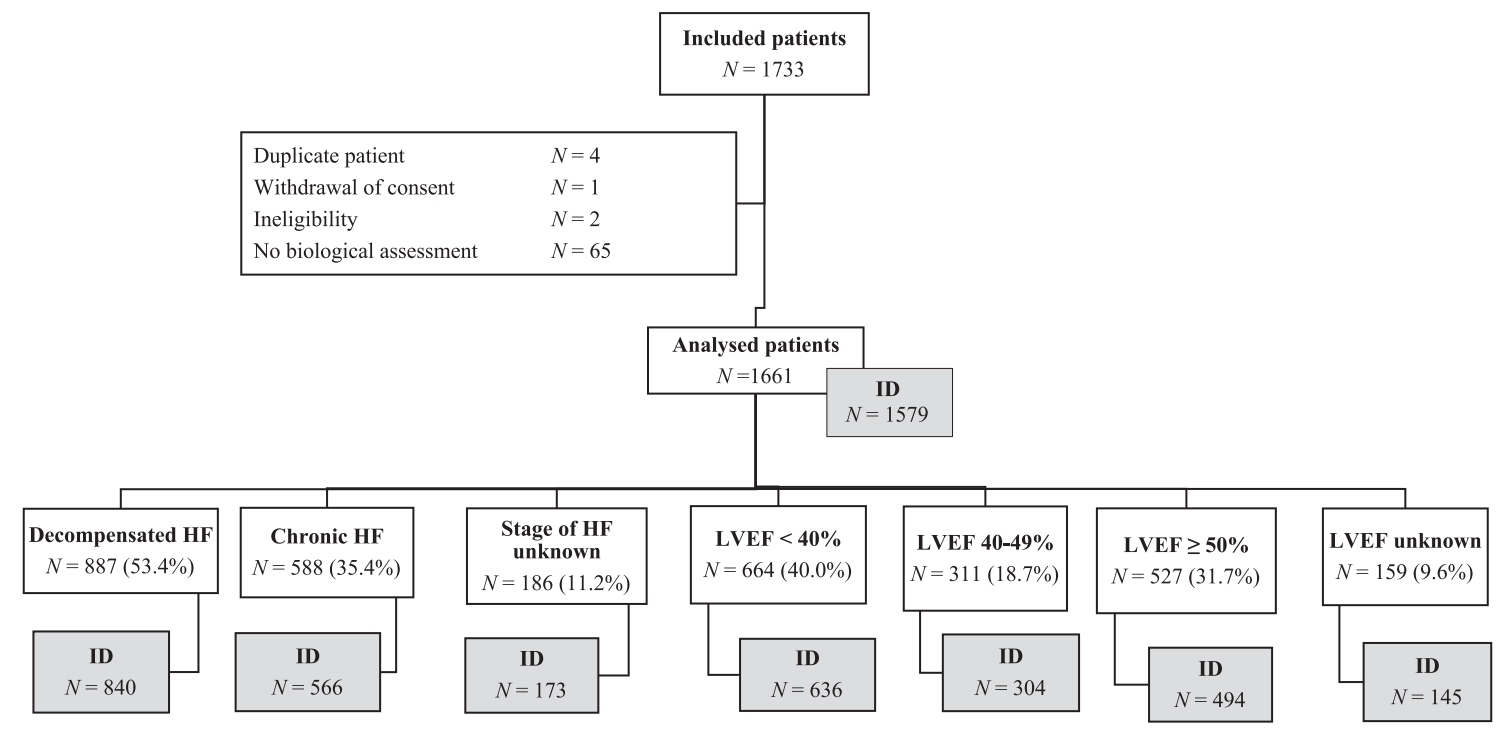


1475 out of the 1661 patients; for the 186 other patients, the reason for admission reported in the questionnaire was not precise enough to decide whether the patient had been hospitalized for cardiac decompensation or not.

Patient's and HF characteristics stratified on the type of HF are presented in Table 1 . Males represented $61.6 \%$ of the study population. The patients' median age was 78 years. More than $83.3 \%$ of the patients had at least one co-morbidity, with hypertension reported in more than $60 \%$ of patients. Decompensated HF represented $60.1 \%$ (887/1475) of cases and CHF 39.9\% (588/1475) of cases. The characteristics of patients who could not be classified as having a CHF or a decompensated $\mathrm{HF}$ are presented in Supporting Information, Table S1.

Patients with a decompensated HF were significantly older than patients with a CHF; they were more likely to be females,

Table 1 Patients' baseline characteristics, and according to the type of heart failure

\begin{tabular}{|c|c|c|c|c|}
\hline & & Type & eart failure ${ }^{a}$ & \\
\hline & Total $(N=1661)$ & Decompensated $(N=887)$ & Chronic $(N=588)$ & $P$-value ${ }^{b}$ \\
\hline $\begin{array}{l}\text { Age (years), } \boldsymbol{n} \\
\text { Median (Q1-Q3) }\end{array}$ & $\begin{array}{c}1661 \\
78.0(67.0-86.0)\end{array}$ & $\begin{array}{c}887 \\
80.0(70.0-87.0)\end{array}$ & $\begin{array}{c}588 \\
72.0(62.0-82.0)\end{array}$ & $<0.001$ \\
\hline Age (in class), $n$ (\%) & 1661 & 887 & 588 & $<0.001$ \\
\hline$<60$ years & $225(13.5)$ & $89(10.0)$ & $121(20.6)$ & \\
\hline [60-70] years & $280(16.9)$ & $125(14.1)$ & 139 (23.6) & \\
\hline [70-80] years & $380(22.9)$ & $205(23.1)$ & $138(23.5)$ & \\
\hline$[80-90]$ years & $585(35.2)$ & 354 (39.9) & $151(25.7)$ & \\
\hline$\geq 90$ years & $191(11.5)$ & $114(12.9)$ & $39(6.6)$ & \\
\hline Gender, $n$ (\%) & 1661 & 887 & 588 & 0.002 \\
\hline Male & $1023(61.6)$ & $528(59.5)$ & $398(67.7)$ & \\
\hline Female & $638(38.4)$ & $359(40.5)$ & $190(32.3)$ & \\
\hline Co-morbidities ${ }^{c}$ & & & & \\
\hline Hypertension, $n$ (\%) & 1661 & 887 & 588 & $<0.001$ \\
\hline No & $618(37.2)$ & $293(33.0)$ & 263 (44.7) & \\
\hline Yes & $1043(62.8)$ & $594(67.0)$ & $325(55.3)$ & \\
\hline Diabetes, $n(\%)$ & 1661 & 887 & 588 & $<0.001$ \\
\hline No & $1118(67.3)$ & $562(63.4)$ & $428(72.8)$ & \\
\hline Yes & $543(32.7)$ & $325(36.6)$ & $160(27.2)$ & \\
\hline Chronic kidney failure, $n$ (\%) & 1661 & 887 & 588 & $<0.001$ \\
\hline No & $1219(73.4)$ & $624(70.3)$ & $468(79.6)$ & \\
\hline Yes & $442(26.6)$ & 263 (29.7) & $120(20.4)$ & \\
\hline Coronary insufficiency, $n$ (\%) & 1661 & 887 & 588 & 0.454 \\
\hline No & $991(59.7)$ & $523(59.0)$ & $359(61.1)$ & \\
\hline Yes & $670(40.3)$ & $364(41.0)$ & 229 (38.9) & \\
\hline Overweight or obesity ${ }^{\mathrm{d}}, n(\%)$ & 1616 & 855 & 581 & 0.126 \\
\hline No & 644 (39.9) & $346(40.5)$ & $211(36.3)$ & \\
\hline Yes & $972(60.1)$ & 509 (59.5) & $370(63.7)$ & \\
\hline Number of co-morbidities, $n(\%)^{\mathrm{e}}$ & 1661 & 887 & 588 & $<0.001$ \\
\hline No co-morbidity & $278(16.7)$ & $130(14.6)$ & $127(21.6)$ & \\
\hline 1 co-morbidity & $541(32.6)$ & $259(29.2)$ & $215(36.6)$ & \\
\hline 2 co-morbidities & $464(27.9)$ & $263(29.7)$ & $148(25.2)$ & \\
\hline 3 co-morbidities & $283(17.0)$ & $179(20.2)$ & $69(11.7)$ & \\
\hline 4 co-morbidities & $95(5.7)$ & $56(6.3)$ & $29(4.9)$ & \\
\hline NYHA class before admission, $n(\%)$ & 1601 & 836 & 579 & $<0.001$ \\
\hline I & $196(12.2)$ & $27(3.2)$ & $136(23.5)$ & \\
\hline II & $604(37.7)$ & $222(26.5)$ & $297(51.3)$ & \\
\hline III & $567(35.4)$ & $390(46.7)$ & $120(20.7)$ & \\
\hline IV & $234(14.6)$ & $197(23.6)$ & $26(4.5)$ & \\
\hline LVEF before admission (\%) & 1502 & 820 & 546 & 0.741 \\
\hline Median (Q1-Q3) & $40.0(30.0-55.0)$ & $40.0(30.0-55.0)$ & $40.0(30.0-52.0)$ & \\
\hline LVEF in class, $\boldsymbol{n}(\%)$ & & & & 0.148 \\
\hline$<40 \%$ & $664(44.2)$ & $371(45.2)$ & $240(44.0)$ & \\
\hline$[40-50] \%$ & $311(20.7)$ & $153(18.7)$ & $125(22.8)$ & \\
\hline$\geq 50 \%$ & $527(35.1)$ & $296(36.1)$ & $181(33.2)$ & \\
\hline
\end{tabular}

HF, heart failure; LVEF, left ventricular ejection fraction; NYHA, New York Heart Association.

Analysable population $N=1661$.

a Patients were classified as having either a chronic HF or a decompensated HF corresponding to patients with acute or chronic HF with an unplanned hospitalization for decompensation.

${ }^{\circ}$ Comparison of clinical characteristics between patients with chronic HF and decompensated HF; Wilcoxon's rank sum test or Pearson's $\chi^{2}$ test.

'Hypertension, diabetes, chronic kidney failure, and coronary insufficiency are diagnoses that were extracted from patients' medical records.

${ }^{d}$ Overweight and obesity were defined as body mass index $25.0-30.0$ and $\geq 30 \mathrm{~kg} / \mathrm{m}^{2}$, respectively.

'Including hypertension, diabetes, chronic kidney failure, and coronary insufficiency. 
to have co-morbidities, and to display NYHA III-IV (Table 1). $\mathrm{HF}$ was classified as HFrEF, HFmrEF, and HFpEF in $44.2 \%$ (664/1502), 20.7\% (311/1502), and 35.1\% (527/1502), respectively. These proportions were not statistically different in patients with a decompensated HF or a CHF. The clinical characteristics of patients according to LVEF profile are presented in Supporting Information, Table S2. Patients with a preserved LVEF were older, more likely to be females, and to have co-morbidities such as hypertension, diabetes, and chronic kidney failure. Proton pump inhibitors and antithrombotic medications used are listed in Supporting Information, Table S3. Ongoing or completed oral iron therapy was recorded in approximately $5 \%$ of patients (Supporting Information, Table S3). Intravenous (IV) iron replacement therapy was recorded in $8.5 \%$ of patients with $\mathrm{CHF}$, and $13.3 \%$ of patients with decompensated HF during the hospital stay; IV ferric carboxymaltose (FCM) was the main treatment.

\section{Body iron parameters, haemoglobin level, and prevalence of iron deficiency}

Table 2 presents the distribution of iron parameters stratified on type of HF. Overall, patients were more likely to have a TSAT index $<20 \%$ than a ferritin level $<100 \mu \mathrm{g} / \mathrm{L}$. The proportion of TSAT $<20 \%$ was statistically higher in decompensated HF (70.0\%) than in CHF (34.7\%) patients $(P<0.001)$, as was the proportion of patients with a ferritin level $<100 \mu \mathrm{g} / \mathrm{L}$ (32.3\% vs. 26.5\%, respectively, $P=0.02$ ) (Figure 2). ID based on the ESC 2016 guidelines could be assessed in $95.1 \%(1579 / 1661)$ of patients. Overall, ID was found in $49.6 \%$ (783/1579, 95\% Cl: 47.1-52.1) of HF patients; females were more likely to have ID than males $(57.9 \%$ vs. 44.4\%, $P<0.001$ ) (Supporting Information, Table S3). ID prevalence was not statistically different in patients from cardiology [49.1\% (46.4-51.8)] and geriatric [51.8\% (45.9-57.7)] units $(P=0.45)$ (data not shown).

\section{Prevalence of iron deficiency according to both types of heart failure and ejection fraction}

Iron deficiency prevalence was statistically higher in decompensated HF (488/840, 58.1\%, 95\% Cl: 54.7-61.4) than in CHF (221/566, 39.0\%, 95\% Cl: 35.1-43.1) (Figure 2, Table 2). A similar trend was observed when stratifying by gender (Supporting Information, Table S4). Anaemia was reported in $59.5 \%$ and $36.1 \%$ of patients with decompensated $\mathrm{HF}$ and $\mathrm{CHF}$, respectively (Table 2). The proportion of patients with TSAT $<20 \%$ and that of patients identified as iron

Table 2 Iron parameters and haemoglobin levels according to type of heart failure (decompensated vs. chronic)

\begin{tabular}{|c|c|c|c|c|}
\hline & \multirow[b]{2}{*}{ Total $(N=1661)$} & \multicolumn{3}{|c|}{ Type of heart failure ${ }^{a}$} \\
\hline & & Decompensated HF $(N=887)$ & Chronic HF $(N=588)$ & $P$-value ${ }^{\mathrm{b}}$ \\
\hline Serum iron $(\mathrm{mg} / \mathrm{L}), n$ & 1583 & 846 & 561 & $<0.001$ \\
\hline Median (IQR) & $0.58(0.39-0.84)$ & $0.49(0.33-0.68)$ & $0.78(0.57-1.00)$ & \\
\hline $\begin{array}{l}\text { Haemoglobin level (g/dL), } n \\
\text { Mean (SD) }\end{array}$ & $\begin{array}{l}1611 \\
12.4(2.1)\end{array}$ & $\begin{array}{l}875 \\
12.1(2.1)\end{array}$ & $\begin{array}{l}554 \\
13.0(2.0)\end{array}$ & $<0.001$ \\
\hline Hb level categories, $n$ (\%) & & 875 & 554 & $<0.001$ \\
\hline$<8 \mathrm{~g} / \mathrm{dL}$ & $21(1.3)$ & $10(1.1)$ & $9(1.6)$ & \\
\hline$[8-10] \mathrm{g} / \mathrm{dL}$ & $225(14.0)$ & $151(17.3)$ & $36(6.5)$ & \\
\hline [10-12] $\mathrm{g} / \mathrm{dL}$ for females, $[10-13] \mathrm{g} / \mathrm{dL}$ for males & $589(36.6)$ & $360(41.1)$ & $155(28.0)$ & \\
\hline$>12 \mathrm{~g} / \mathrm{dL}$ for females, $>13 \mathrm{~g} / \mathrm{dL}$ for males & $776(48.2)$ & $354(40.5)$ & $354(63.9)$ & \\
\hline Serum ferritin level $(\mu \mathrm{g} / \mathrm{L}), n$ & 1582 & 842 & 567 & 0.193 \\
\hline Median (IQR) & $195.5(85.0-375.0)$ & $174.0(78.0-364.0)$ & $209.0(93.0-367.0)$ & \\
\hline Serum ferritin level categories, $\boldsymbol{n}(\%)$ & 1582 & 842 & 567 & 0.022 \\
\hline$<100 \mu \mathrm{g} / \mathrm{L}$ & $459(29.0)$ & $272(32.3)$ & $150(26.5)$ & \\
\hline$\geq 100 \mu \mathrm{g} / \mathrm{L}$ & $1123(71.0)$ & $570(67.7)$ & $417(73.5)$ & \\
\hline TSAT (\%), $n$ & 1593 & 848 & 568 & $<0.001$ \\
\hline Median (IQR) & $18.0(12.0-26.0)$ & $15.0(10.0-21.0)$ & $23.0(17.0-30.0)$ & \\
\hline TSAT categories, $n(\%)$ & 1593 & 848 & 568 & $<0.001$ \\
\hline$<20 \%$ & $894(56.1)$ & $594(70.0)$ & $197(34.7)$ & \\
\hline$\geq 20 \%$ & $699(43.9)$ & $254(30.0)$ & $371(65.3)$ & \\
\hline ID prevalence ${ }^{c}$ & 1579 & 840 & 566 & $<0.001$ \\
\hline No, $n(\%)$ & $796(50.4)$ & $352(41.9)$ & $345(61.0)$ & \\
\hline Yes, $n(\%)[95 \% \mathrm{Cl}]$ & $783(49.6)[47.1-52.1]$ & 488 (58.1) [54.7-61.4] & $221(39.0)$ [35.1-43.1] & \\
\hline
\end{tabular}

$\mathrm{Cl}$, confidence interval; $\mathrm{Hb}$, haemoglobin; $\mathrm{HF}$, heart failure; ID, iron deficiency; IQR, interquartile range; SD, standard deviation; TSAT, iron saturation of transferrin.

Analysable population $N=1661$.

${ }^{a}$ Patients were classified as having either a chronic HF or a decompensated HF corresponding to patients with acute or chronic HF with an unplanned hospitalization for decompensation.

${ }^{\circ}$ Comparison of biological characteristics between patients with chronic HF and decompensated HF; Wilcoxon's rank sum test or Pearson's $\chi^{2}$ test.

'Based on the European Society of Cardiology 2016 guidelines. 
Figure 2 Prevalence of iron deficiency (ID), absolute and functional ID, and TSAT $<20 \%$ according to the stage of heart failure (decompensated vs. chronic HF). Analysable population $N=1475$. ESC, European Society of Cardiology; TSAT, iron saturation of transferrin.

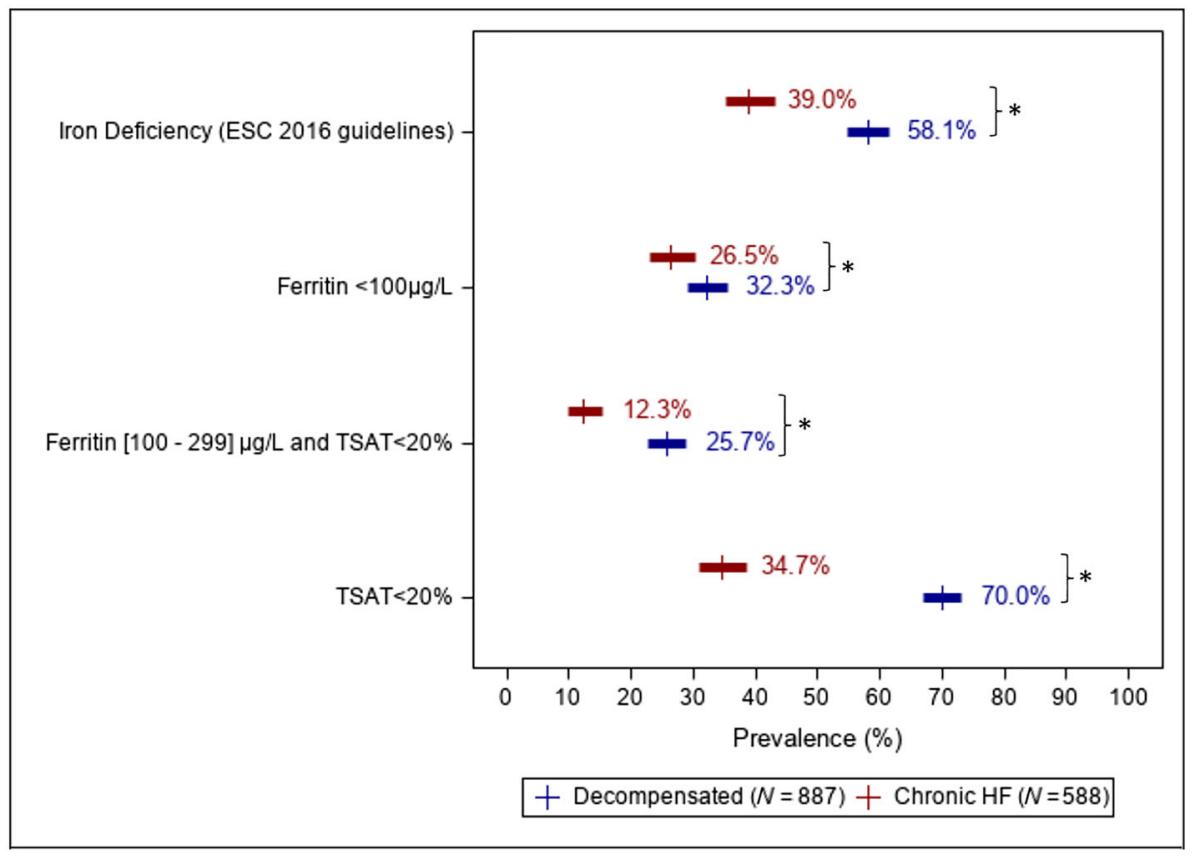

deficient based on the ESC criteria were compared: among CHF patients, the level of agreement between TSAT $<20 \%$ alone and ID was considered as substantial [kappa coefficient, 95\% Cl: 0.65 (0.58-0.72)], while it was considered as moderate among patients with decompensated HF [kappa coefficient, $95 \% \mathrm{Cl}: 0.58(0.52-0.63)$ ], with a higher proportion of patients with a TSAT $<20 \%(70.0 \%)$ than with ID based on the ESC criteria (58.1\%).

Iron deficiency prevalence was determined in 1434/1502 $(95.5 \%)$ of patients with a documented LVEF. Patients with a preserved LVEF were significantly more likely to have an ID (284/494, 57.5\%, 95\% Cl: 53.1-61.8) compared with patients with mildly reduced (144/304, 47.4\%, 95\% $\mathrm{Cl}$ : 45.7-65.0) or reduced LVEF (282/636, 44.3\%, 95\% Cl: 40.5-48.2) (Figure 3, Supporting Information, Table S2).

\section{Clinical practices}

Clinical practices regarding iron assessment were documented in all participating centres. Twenty-eight out of the 48 centres (58.3\%) reported a systematic iron assessment for patients with CHF; 25 centres (25/47, 53.2\%) reported a systematic iron assessment in patients with decompensated HF. Iron assessment was most likely performed on admission than at the end of hospitalization both in patients with decompensated HF $(21 / 28,80.8 \%)$ and in those with $\mathrm{CHF}$ $(20 / 25,80.0 \%)$; only two centres $(2 / 28,7.7 \%)$ reported iron assessment before admission for patients with CHF. Most of the centres declared measuring serum ferritin, TSAT, and $\mathrm{Hb}$ levels both in patients with decompensated HF (between $96 \%$ and $100 \%$ of the centres) and in patients with $\mathrm{CHF}$ (100\% of the centres); serum iron was documented in only $58.3 \%$ and $62.5 \%$ of centres in case of $\mathrm{CHF}$ and decompensated HF, respectively.

\section{Discussion}

We prospectively assessed ID prevalence in a large cohort of patients presenting at hospital with diverse HF types, with a systematic measurement of both ferritin level and TSAT index. We showed that as many as $49.6 \%$ of $\mathrm{HF}$ patients presented with ID based on the 2016 ESC definition. Absolute ID accounted for the majority (59\%) of all ID cases. ID prevalence was significantly higher in decompensated HF than in CHF. In decompensated HF, the agreement between a TSAT index $<20 \%$ and ID based on the ESC criteria was considered as moderate. Importantly, patients with a mildly reduced LVEF were significantly more likely to have an ID compared with patients with reduced LVEF. Patients with preserved LVEF had even higher rates of ID than patients with HFmrEF.

The prevalence of ID has mainly been estimated in stable CHF patients, ambulatory or hospitalized, in whom it is considered as one of the most common non-cardiovascular co-morbidities. In these patients, it has been shown that the prevalence of ID varies according to gender, NYHA 
Figure 3 Prevalence of iron deficiency (ID), absolute and functional ID, and TSAT $<20 \%$ according to left ventricular ejection fraction (LVEF). Analysable population $N=1502$. LVEF before admission was categorized as preserved ( $\geq 50 \%$ ), mildly reduced (40-49\%), or reduced ( $<40 \%)$. ID was defined as a serum ferritin level $<100 \mu \mathrm{g} / \mathrm{L}$ or the combination of a serum ferritin level between 100 and $299 \mu \mathrm{g} / \mathrm{L}$ and a TSAT index $<20 \%$; absolute ID was defined as a serum ferritin $<100 \mu \mathrm{g} / \mathrm{L}$; and functional ID was defined as the combination of a serum ferritin level between 100 and $299 \mu \mathrm{g} / \mathrm{L}$ and a TSAT index $<20 \%$. Prevalence estimates were compared between patients according to LVEF profile using the $\chi^{2}$ test; an asterisk indicates a $P$-value $<0.05$. ESC, European Society of Cardiology; TSAT, iron saturation of transferrin.

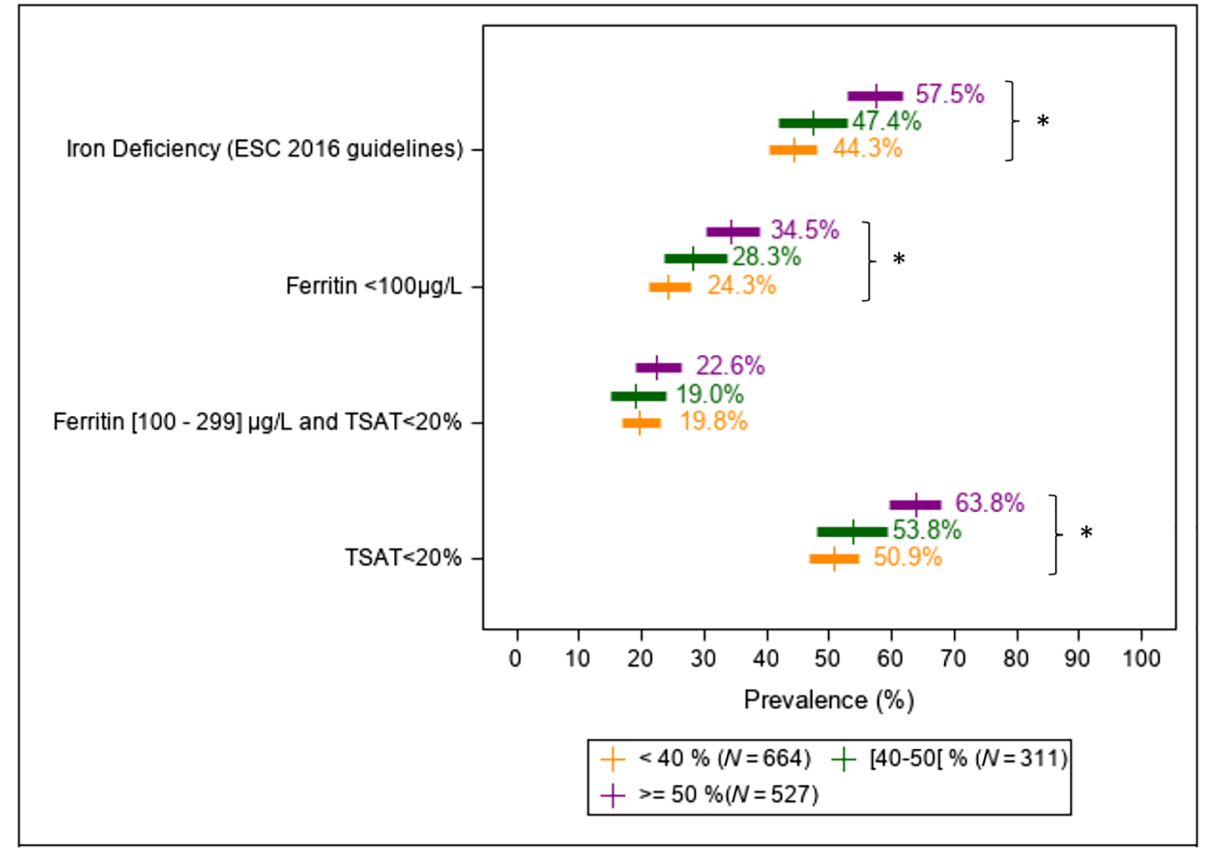

category, anaemia, and LVEF, ranging from $30 \%$ to $55 \%,{ }^{3,18}$ and that the figures are higher than those for chronic obstructive pulmonary disease, renal failure or diabetes, and other common co-morbidities in HF. In accordance with the literature, we found that $39.0 \%$ of $\mathrm{CHF}$ patients had an ID. There are less data available on the prevalence of ID in decompensated HF patients, who represented $60.1 \%$ of our study population. Compared with CHF patients, those with a decompensated HF had a much higher prevalence of ID (58.1\%) that is in concordance with previously reported prevalence estimates. ${ }^{4,19,20}$ Recently, it has been shown that treatment of ID in patients with LVEF $<50 \%$ hospitalized for HF decompensation (AFFIRM-HF study) resulted in a reduction in $\mathrm{HF}$ hospitalizations. ${ }^{21}$ There is now a class Ila level B in the 2021 ESC guidelines to consider IV FCM in patients hospitalized for acute HF before discharge to improve symptoms and reduce rehospitalization. ${ }^{13}$ Thirty-six per cent (524/1475) of our study population had similar characteristics than patients included in the AFFIRM-HF trial and may have benefited from IV FCM based on the 2021 ESC guidelines.

We showed that prevalence estimates of ID were higher in patients with HFpEF and HFmrEF compared with patients with HFrEF. This finding is in line with those of recent publications $^{7,22}$ and meta-analyses. ${ }^{6}$ Recently, Martens et al. reported ID prevalence as high as $64 \%$ and $61 \%$ in $\mathrm{CHF}$ patients with HFpEF and HFmrEF, respectively. ${ }^{7}$ The reason for this is not clear. Higher age and a higher proportion of women and patients with co-morbidities alone do not explain this finding. In patients with HFpEF and HFmrEF, ID has been associated with reduced exercise capacity and quality of life as in HFrEF. ${ }^{7,22}$ Systematic assessment of iron status and iron supplementation may therefore be relevant in these patients, for whom there is no clear recommendation for management.

Indeed, there is now clear evidence that IV iron therapy in CHF patients has positive effects on both symptoms related to ID, including quality of life, and risk of HF-related hospitalization. ${ }^{23,24}$ The ESC guidelines propose that this treatment should be offered in symptomatic patients with HFrEF and ID. ${ }^{2}$ There are currently no recommendations for $\mathrm{CHF}$ patients with HFpEF. ${ }^{13}$ Three clinical trials (NCT03074591, NCT03833336, and NCT04945707) are underway to assess the efficacy of IV iron therapy in these patients -who represent a significant proportion of the iron-deficient population and have similar morbidity and mortality rates than HFrEF patients ${ }^{6}$ on exercise capacity and quality of life. In particular, the large FAIR-HFpEF trial will assess the effect of FCM on exercise tolerance, symptoms, and quality of life in patients with HFpEF and ID (NCT03074591).

We found a higher prevalence of ID defined by TSAT alone than by the ESC criteria in patients with decompensated HF. Among these patients, $70 \%$ had a TSAT index $<20 \%$ while 
58.1\% were diagnosed iron deficient based on the ESC 2016 criteria, reflected by only a moderate level of agreement between TSAT alone and the ESC criteria. Among patients with $\mathrm{CHF}$, the level of agreement between TSAT $<20 \%$ and ID (ESC criteria) was higher and considered as substantial. Although a higher prevalence of TSAT $<20 \%$ compared with the ESC criteria does not imply that the former definition is the most accurate, our results are in line with recent publications highlighting the diagnostic and predictive value of TSAT. Recently, Beverborg et al. reported that low TSAT better correlated than ferritin to characterize ID when taking bone marrow iron content as reference. ${ }^{25}$ Also, Cleland et al. showed that serum concentrations of iron and TSAT were more strongly associated with anaemia than were serum concentrations of ferritin. ${ }^{26}$ Finally, a low TSAT has been independently associated with higher rates of morbidity and death. ${ }^{25-28}$ All together, these results reinforce the idea of using a TSAT $<20 \%$ for the identification of ID in patients with $\mathrm{HF}$ and question the value of serum ferritin in the assessment of ID. ${ }^{29,30}$

Despite the demonstrated adverse effects of ID in HF patients, the diagnosis and management of HF patients with ID remain largely suboptimal. ${ }^{15,31} \mathrm{~A}$ recent study based on French healthcare databases including more than 100000 patients undergoing iron therapy from 2006 to 2015 showed that ID was highly under-detected, with iron assessment reported in only $33 \%$ of patients before iron therapy. ${ }^{15}$ In the present study, clinical practices were evaluated in each of the 48 participating centres. Just over $50 \%$ of them reported a systematic iron assessment in both CHF patients and those with decompensated HF. Although these results may not be representative of the clinical practices of all practitioners in the centres, they highlight the strong under-detection of ID even in highly specialized units. This may be partially due to the lack of practical advice on how to screen, diagnose, and treat ID, in particular in acute $\mathrm{HF}^{32}$

We acknowledge some limitations to the present study. First, our prevalence estimates are not based on a representative sample of HF patients. However, they are based on a very large number of participants recruited from 48 centres across France. The diagnosis of HF was based on the patient's medical record and did not have to meet any specific criteria for the study. However, as most of the participants were inpatients in cardiology units, we are confident in the validity of the HF diagnosis. Eleven per cent of the participants could not be classified as having a decompensated HF or a CHF based on the reason for admission but still contributed to the estimated prevalence of ID in the overall study population. Second, biochemical assessment was not centralized, with possibly different biological cut-offs across participating centres. Therefore, misclassifications cannot be excluded. Only serum ferritin and TSAT levels were determined because they are the two biomarkers recommended by the ESC and the French National Authority for Health to define ID. Finally, the values of the iron parameters prior to decompensation were not reported. Therefore, it is not known whether ID in patients with decompensated HF was already present before decompensation.

\section{Conclusion}

In this large, nationwide study, we found a high prevalence of ID in patients with HF. While most studies have addressed the prevalence of ID in patients with $\mathrm{CHF}$ and low EF, we found that ID prevalence was significantly higher in HFmrEF and HFpEF or in decompensated HF. We also found that ID when defined only by low TSAT, a definition supported by recent studies and overcoming the limitation of ferritin assessment in case of inflammation, was higher than when defined by the ESC criteria in patients with decompensated HF. Finally, our study reveals an insufficient application of the ESC guidelines regarding systematic detection of ID and anaemia in all HF patients using both serum ferritin concentration and TSAT. ${ }^{13}$

\section{Acknowledgements}

We are extremely grateful to all patients who took part in this study and to all CARENFER research teams for recruiting and following them. We also thank Valérie Briand (IQVIA) for reviewing the manuscript.

\section{Conflict of interest}

P. Cacoub received grants from Alnylam and MSD; royalties from Iltoo; consulting fees from Vifor Pharma and Servier; honoraria from Vifor Pharma, Servier, and Alnylam; and support for attending meetings from Abbvie. J.N. Trochu received consulting fees and clinical research grant from Vifor Pharma for the present work; institutional grants from Novartis, Akcea, and Boston Scientific; consulting fees from Novartis, Bayer, Resmed, Astra Zeneca, and Abbott; and honoraria from Abbott and Novartis. A. Korichi has a full-time position at Vifor Pharma Group. Alain Cohen Solal received in the last 3 years fees for expertises, boards, and studies from Novartis, Vifor Pharma, We Health, Bayer, Abbott, Merck, Astra Zeneca, Leo, Boehringer Ingelheim, and Sanofi. F. Picard received personal fees from Vifor Pharma for the present study. All remaining authors have declared no conflicts of interest. 


\section{Funding}

This work was supported by Vifor Pharma Group (no grant number), which contributed to the statistical analysis with the support of IQVIA Operations France.

\section{Author contributions}

Conceptualization: A. Cohen-Solal (ACS), P. Cacoub (PC), and J.-N. Trochu (JNT). Investigation: ACS, J.-L. Philip (JLP), F. Picard (FP), N. Delarche (ND), G. Taldir (GT), H. Gzara (HG), JNT, PC, and the CARENFER Study Group. Supervision: ACS, JLP, FP, ND, GT, HG, JNT, PC, and A. Korichi (AK). Statistical analysis: Vifor Pharma Group and IQVIA Operations France. Data interpretation: ACS, JLP, FP, ND, GT, HG, JNT, PC, and AK. Roles/writing-original draft: ACS, PC, and JNT. Writing - review and editing: ACS, JLP, FP, ND, GT, HG, JNT, PC, AK, and the CARENFER Study Group.

\section{Supporting information}

Additional supporting information may be found online in the Supporting Information section at the end of the article.

Table S1. Patients' baseline characteristics according to whether the type of heart failure (decompensated vs. chronic) was determined. Analyzable population $N=1661^{\$}$.

Table S2. Patients' clinical characteristics and iron parameters and haemoglobin levels according to LVEF profile. Analyzable population $N=1502$.

Table S3. Current treatment for heart failure (HF) and current or completed treatment for iron deficiency (ID) according to the type of heart failure (decompensated vs. chronic HF). Analyzable Population $N=1475$.

Table S4. Iron parameters and haemoglobin levels according to gender and type of heart failure ". Analyzable Population $N=1475$.

\section{References}

1. van Deursen VM, Urso R, Laroche C, Damman K, Dahlström U, Tavazzi L, Maggioni AP, Voors AA. Co-morbidities in patients with heart failure: an analysis of the European Heart Failure Pilot Survey. Eur J Heart Fail 2014; 16: 103-111.

2. Ponikowski P, Voors AA, Anker SD, Bueno H, Cleland JGF, Coats AJS, Falk V, González-Juanatey JR, Harjola VP, Jankowska EA, Jessup M, Linde C, Nihoyannopoulos P, Parissis JT, Pieske B, Riley JP, Rosano GMC, Ruilope LM, Ruschitzka F, Rutten FH, van der Meer P, ESC Scientific Document Group. 2016 ESC Guidelines for the diagnosis and treatment of acute and chronic heart failure: the Task Force for the diagnosis and treatment of acute and chronic heart failure of the European Society of Cardiology (ESC)Developed with the special contribution of the Heart Failure Association (HFA) of the ESC. Eur Heart J 2016; 37: 2129-2200 Available from.

3. Klip IT, Comin-Colet J, Voors AA, Ponikowski P, Enjuanes C, Banasiak W, Lok DJ, Rosentryt P, Torrens A, Polonski L, van Veldhuisen DJ, van der Meer P, Jankowska EA. Iron deficiency in chronic heart failure: an international pooled analysis. Am Heart $J$ 2013; 165 : 575-582.e3.

4. Cohen-Solal A, Damy T, Terbah M, Kerebel S, Baguet J-P, Hanon O, Zannad F, Laperche T, Leclercq C, Concas V, Duvillié L, Darné B, Anker S, Mebazaa A. High prevalence of iron deficiency in patients with acute decompensated heart failure. Eur J Heart Fail 2014; 16: 984-991.

5. Sportouch L, Cautela J, Resseguier N, Pinto J, Ammar C, Gaubert M, Barraud J, Peyrol M, Laine M, Bonello L, Yvorra S, Paganelli F, Thuny F. Dynamic iron status after acute heart failure. Arch Cardiovasc Dis 2019; 112: 410-419.

6. Beale AL, Warren JL, Roberts N, Meyer P, Townsend NP, Kaye D. Iron deficiency in heart failure with preserved ejection fraction: a systematic review and metaanalysis. Open Heart 2019; 6: e001012.

7. Martens P, Nijst P, Verbrugge FH, Smeets K, Dupont M, Mullens W. Impact of iron deficiency on exercise capacity and outcome in heart failure with reduced, mid-range and preserved ejection fraction. Acta Cardiol 2018; 73: 115-123.

8. Enjuanes C, Bruguera J, Grau M, Cladellas M, Gonzalez G, Meroño O, Moliner-Borja P, Verdú JM, Farré N, Comín-Colet J. Iron status in chronic heart failure: impact on symptoms, functional class and submaximal exercise capacity. Rev Esp Cardiol (Engl Ed) 2016; 69: 247-255.

9. Jankowska EA, Rozentryt P, Witkowska A, Nowak J, Hartmann O, Ponikowska B, Borodulin-Nadzieja L, von Haehling S, Doehner W, Banasiak W, Polonski L, Filippatos G, Anker SD, Ponikowski P. Iron deficiency predicts impaired exercise capacity in patients with systolic chronic heart failure. J Card Fail 2011; 17: 899-906.

10. Enjuanes C, Klip IT, Bruguera J, Cladellas M, Ponikowski P, Banasiak W, van Veldhuisen DJ, van der Meer P, Jankowska EA, Comín-Colet J. Iron deficiency and health-related quality of life in chronic heart failure: results from a multicenter European study. Int $J$ Cardiol 2014; 174: 268-275.

11. Comín-Colet J, Martín Lorenzo T, González-Domínguez A, Oliva J, Jiménez Merino S. Impact of non-cardiovascular comorbidities on the quality of life of patients with chronic heart failure: a scoping review. Health Qual Life Outcomes 2020; 18: 329.

12. Anand IS, Gupta P. Anemia and iron deficiency in heart failure: current concepts and emerging therapies. Circulation 2018; 138: 80-98.

13. Rosano GMC. Preview of the 2021 ESC/ HFA heart failure guidelines. Available at https://pace-cme.org/2021/06/29/ preview-of-the-2021-esc-hfa-heart-failure-guidelines/. (Accessed August $1^{\text {st }}$, 2021).

14. French National Authority for Health (Haute Autorité de Santé, France). Choix des examens du métabolisme du fer en cas de suspicion de crence en fer - Rapport d'évaluation. (2011). Available at https://www.has-sante.fr/ portail/jcms/c_1051506/fr/choix-desexamens-du-metabolisme-du-fer-en-casde-suspicion-de-carence-en-fer-rapportd-evaluation. 2011. (Accessed August $1^{\text {st, } 2021)}$

15. Cacoub P, Nicolas G, Peoc'h K. Iron deficiency markers in patients undergoing iron replacement therapy: a 9-year retrospective real-world evidence study 
using healthcare databases. Sci Rep 2020; 10: 14983.

16. Beale AL, Meyer P, Marwick TH, Lam CSP, Kaye DM. Sex differences in cardiovascular pathophysiology: why women are overrepresented in heart failure with preserved ejection fraction. Circulation 2018; 138: 198-205.

17. Agresti A, Coull BA. Approximate is better than "exact" for interval estimation of binomial proportions. Am Stat 1998; 52: 119-126; Available at https://math. unm.edu/ james/Agresti1998.pdf Accessed August 1st, 2021.

18. Rocha BML, Cunha GJL, Menezes Falcão LF. The burden of iron deficiency in heart failure: therapeutic approach. $J$ Am Coll Cardiol 2018; 71: 782-793.

19. Núñez J, Comín-Colet J, Miñana G, Núñez E, Santas E, Mollar A, Valero E, García-Blas S, Cardells I, Bodí V, Chorro FJ, Sanchis J. Iron deficiency and risk of early readmission following a hospitalization for acute heart failure. Eur $J$ Heart Fail 2016; 7: 798-802.

20. Van Aelst LNL, Abraham M, Sadoune M, Lefebvre T, Manivet $\mathrm{P}$, Logeart D, Launay JM, Karim Z, Puy H, Cohen-Solal A. Iron status and inflammatory biomarkers in patients with acutely decompensated heart failure: early in-hospital phase and 30-day follow-up. Eur J Heart Fail 2017; 19: 1075-1076.

21. Ponikowski P, Kirwan B-A, Anker SD, McDonagh T, Dorobantu M, Drozdz J, Fabien V, Filippatos G, Göhring UM, Keren A, Khintibidze I, Kragten $\mathrm{H}$, Martinez FA, Metra M, Milicic D, Nicolau JC, Ohlsson M, Parkhomenko A, PascualFigal DA, Ruschitzka F, Sim D, Skouri H, van der Meer P, Lewis BS, Comin-Colet $\mathrm{J}$, von Haehling $\mathrm{S}$, Cohen-Solal A, Danchin N, Doehner W, Dargie HJ, Motro M, Butler J, Friede T, Jensen KH, Pocock S, Jankowska EA, Azize G, Fernandez A, Zapata GO, Garcia Pacho P, Glenny A, Ferre Pacora F, Parody ML, Bono J, Beltrano C, Hershson A, Vita N, Luquez HA, Cestari HG, Fernandez H, Prado A, Berli M, García Durán R, Thierer J, Diez M, Lobo Marquez L, Borelli RR, Hominal MÁ, Metra M, Ameri P, Agostoni P, Salvioni A, Fattore L, Gronda E, Ghio S, Turrini F, Uguccioni M, di Biase M, Piepoli M, Savonitto S, Mortara A, Terrosu P, Fucili A, Boriani G, Midi P, Passamonti E, Cosmi F, van der Meer P, van Bergen $\mathrm{P}$, van de Wetering $\mathrm{M}$, alWindy NYY, Tanis W, Meijs M, Groutars RGEJ, The HKS, Kietselaer B, van Kesteren H, Beelen DPW, Heymeriks J, van de Wal R, Schaap J, Emans M, Westendorp P, Nierop PR, Nijmeijer R, Manintveld OC, Dorobantu M, Darabantiu DA, Zdrenghea D, Toader DM, Petrescu L, Militaru C, Crisu D,
Tomescu MC, Stanciulescu G, Rodica Dan A, Iosipescu LC, Serban DL, Drozdz J, Szachniewicz J, Bronisz M, Tycińska A, Wozakowska-Kaplon B, MirekBryniarska E, Gruchała M, Nessler J, Straburzyńska-Migaj E, Mizia-Stec K, Szelemej R, Gil R, Gąsior M, Gotsman I, Halabi M, Shochat M, Shechter $M$, Witzling V, Zukermann R, Arbel Y, Flugelman M, Ben-Gal T, Zvi V, Kinany W, Weinstein JM, Atar S, Goland S, Milicic D, Horvat D, Tušek S, Udovicic M, Sutalo K, Samodol A, Pesek K, Artuković M, Ružić A, Šikić J, McDonagh T, Trevelyan J, Wong YK, Gorog D, Ray R, Pettit S, Sharma S, Kabir A, Hamdan H, Tilling L, Baracioli L, Nigro Maia L, Dutra O, Reis G, Pimentel Filho P, Saraiva JF, Kormann A, dos Santos F, Bodanese L, Almeida D, Precoma D, Rassi S, Costa F, Kabbani S, Abdelbaki K, Abdallah C, Arnaout MS, Azar R, Chaaban S, Raed O, Kiwan G, Hassouna B, Bardaji A, Zamorano J, del Prado S, Gonzalez Juanatey JR, Ga Bosa Ojeda FI, Gomez Bueno M, Molina BD, Pascual Figal DA, Sim D, Yeo TJ, Loh SY, Soon D, Ohlsson M, Smith JG, Gerward S, Khintibidze I, Lominadze Z, Chapidze G, Emukhvari N, Khabeishvili G, Chumburidze V, Paposhvili K, Shaburishvili T, Khabeishvili G, Parhomenko O, Kraiz I, Koval O, Zolotaikina V, Malynovsky Y, Vakaliuk I, Rudenko L, Tseluyko V, Stanislavchuk M. Ferric carboxymaltose for iron deficiency at discharge after acute heart failure: a multicentre, double-blind, randomised, controlled trial. Lancet 2020; 396: 1895-1904.

22. Bekfani T, Pellicori P, Morris D, Ebner N, Valentova M, Sandek A, Doehner W, Cleland JG, Lainscak M, Schulze PC, Anker SD, von Haehling S. Iron deficiency in patients with heart failure with preserved ejection fraction and its association with reduced exercise capacity, muscle strength and quality of life. Clin Res Cardiol 2019; 108: 203-211.

23. Anker SD, Kirwan B-A, van Veldhuisen DJ, Filippatos G, Comin-Colet J, Ruschitzka F, Lüscher TF, Arutyunov GP, Motro M, Mori C, Roubert B, Pocock SJ, Ponikowski P. Effects of ferric carboxymaltose on hospitalisations and mortality rates in iron-deficient heart failure patients: an individual patient data meta-analysis. Eur $J$ Heart Fail 2018; 20: 125-133.

24. Jankowska EA, Tkaczyszyn M, Suchocki T, Drozd M, von Haehling S, Doehner W, Banasiak W, Filippatos G, Anker SD, Ponikowski P. Effects of intravenous iron therapy in iron-deficient patients with systolic heart failure: a meta-analysis of randomized controlled trials. Eur $J$ Heart Fail 2016; 18: 786-795.
25. Beverborg NG, van der Wal HH, IjT K, Anker SD, Cleland J, Dickstein K, van Veldhuisen DJ, Voors AA, van der Meer P. Differences in clinical profile and outcomes of low iron storage vs defective iron utilization in patients with heart failure: results from the DEFINE-HF and BIOSTAT-CHF studies. JAMA Cardiol 2019; 4: 696-701.

26. Cleland JGF, Zhang J, Pellicori P, Dicken B, Dierckx R, Shoaib A, Wong K, Rigby A, Goode K, Clark AL. Prevalence and outcomes of anemia and hematinic deficiencies in patients with chronic heart failure. JAMA Cardiol 2016; 1: 539-547.

27. Ambrosy AP, Fitzpatrick JK, Tabada GH, Gurwitz JH, Artz A, Schrier SL, Rao SV, Reynolds K, Smith DH, Peterson PN, Fortmann SP, Sung SH, Cohen HJ, Go AS. A reduced transferrin saturation is independently associated with excess morbidity and mortality in older adults with heart failure and incident anemia. Int J Cardiol 2020; 309: 95-99.

28. Moliner P, Jankowska EA, van Veldhuisen DJ, Farre N, Rozentryt P, Enjuanes C, Polonski L, Meroño O, Voors $\mathrm{AA}$, Ponikowski $\mathrm{P}$, van der Meer $\mathrm{P}$, Comin-Colet J. Clinical correlates and prognostic impact of impaired iron storage versus impaired iron transport in an international cohort of 1821 patients with chronic heart failure. Int $J$ Cardiol 2017; 243: 360-366.

29. Cacoub P, Vandewalle C, Peoc'h K. Using transferrin saturation as a diagnostic criterion for iron deficiency: a systematic review. Crit Rev Clin Lab Sci 2019; 56: 526-532 Available from:.

30. Peyrin-Biroulet L, Williet N, Cacoub P. Guidelines on the diagnosis and treatment of iron deficiency across indications: a systematic review. Am J Clin Nutr 2015; 102: 1585-1594.

31. Wienbergen $\mathrm{H}$, Pfister $\mathrm{O}$, Hochadel $\mathrm{M}$, Michel S, Bruder O, Remppis BA, Maeder MT, Strasser R, von Scheidt W, Pauschinger M, Senges J, Hambrecht R, RAID-HF (Registry Analysis of Iron Deficiency-Heart Failure) REGISTRY Study Group. Usefulness of iron deficiency correction in management of patients with heart failure [from the Registry Analysis of Iron Deficiency-Heart Failure (RAID-HF) registry]. Am $J$ Cardiol 2016; 118: 1875-1880.

32. McDonagh T, Damy T, Doehner W, Lam CSP, Sindone A, van der Meer P, Cohen-Solal A, Kindermann I, Manito $\mathrm{N}$, Pfister $\mathrm{O}$, Pohjantähti-Maaroos $\mathrm{H}$, Taylor J, Comin-Colet J. Screening, diagnosis and treatment of iron deficiency in chronic heart failure: putting the 2016 European Society of Cardiology heart failure guidelines into clinical practice. Eur J Heart Fail 2018; 20: 1664-1672. 


\section{Appendix A: CARENFER Study Group members (alphabetical order)}

All members contributed as authors for this work.

Dr Franck Albert, Centre Hospitalier de Chartres, Chartres, France.

Prof. Fabrice Bauer, CHU de Rouen, Rouen, France.

Prof. Gilles Berrut, Centre Hospitalier Bellier, CHU de Nantes, Nantes, France.

Dr Nicolas Bihry, Centre Hospitalier Saint Joseph Saint Luc, Lyon, France.

Prof. Hubert Blain, Centre Antonin Balmes, CHU de Montpellier, Montpellier, France.

Dr Emmanuel Boiffard, Centre Hospitalier Départemental Vendée, la Roche-sur-Yon, France.

Dr Nicolas Bourrely, Centre Hospitalier de Mulhouse, Mulhouse, France.

Dr Gilles Brierre, Centre Hospitalier du Val d'Ariège, Saint-Jean De Verges, France.

Prof. Patrice Cacoub, Groupe Hospitalier Pitié-Salpêtrière, AP-HP, Paris, France.

Dr Mathieu Chacornac, Centre Hospitalier Annecy, Annecy, France.

Prof. Alain Cohen-Solal, Hôpital Lariboisière, Paris, France.

Prof. Yves Cottin, Hôpital du Bocage, Dijon, France.

Dr Nicolas Delarche, Centre Hospitalier de Pau, Pau, France.

Dr Julia Desbonnet, CHU Clermont-Ferrand, ClermontFerrand, France.

Dr Elena Dimitriu, Hôpital Nord Franche-Comté, Trévenans, France.

Prof. Erwan Donal, CHU de Rennes, Rennes, France.

Dr Guillaume Duchet, Hôpital la Chataigneraie, ClermontFerrand, France.

Dr Jean Christophe Eicher, Hôpital du Bocage, Dijon, France.

Prof. Michel Galinier, Hôpital Rangueil, CHU de Toulouse, Toulouse, France.

Dr Cédric Gaxatte, Hôpiral Roger Salengro, Lille, France.

Dr Marc Goralski, Centre Hospitalier Orléans, Orléans, France.

Dr Heger Gzara, Hôpital Sud-Francilien, Corbeil-Essonnes, France.

Dr Sanaa Hannat, Hôpital Sud, CHU Amiens, Amiens, France.

Prof. Olivier Hanon, Hôpital Broca, AP-HP, Paris, France.

Dr Laurence Herrou-Roupie, CHU de Caen, Caen, France.
Prof. Richard Isnard, Groupe Hospitalier Pitié-Salpêtrière, AP-HP, Paris, France.

Prof. Pierre Jouanny, Centre de Champmaillot, $\mathrm{CHU}$ de Dijon, Dijon, France.

Dr Nadir Kadri, Hôpital Saint-Julien, CHU de Rouen, Rouen, France.

Dr David Kenizou, Centre Hospitalier de Mulhouse, Mulhouse, France.

Dr Cédric Le Guillou, CHU de Nîmes, Nîmes, France.

Dr Damien Legallois, CHU de Caen, Caen, France.

Dr Benoît Lequeux, CHU de Poitiers, Poitiers, France.

Dr Bruno Maillier, Centre Hospitalier de Troyes, Troyes, France.

Prof. Isabelle Marchasson-Bourdel, Centre Henri Choussat, CHU de Bordeaux, Bordeaux, France.

Prof. Damien Metz, CHU Robert Debré, Reims, France.

Dr Basile Mouhat, $\mathrm{CHU}$ de Besançon, Besançon, France.

Prof. Jean-Luc Novella, CHU de Reims, Reims, France.

Dr Vuthik Panh, Centre Hospitalier Alpes-Léman, Contamine sur Arve, France.

Prof. Eric Pautas, Hôpital Charles-Foix, Groupe Hospitalier Pitié-Salpêtrière, AP-HP, Paris, France.

Prof. Alain Pesce, Centre Hospitalier Princesse Grace, Monaco.

Dr François Picard, Hôpital Haut-Lévêque, CHU de Bordeaux, Bordeaux, France.

Dr Mélissa Pierre, CHU de Caen, Caen, France.

Dr Jean-Luc Philip, Centre Hospitalier de Chalon, Chalon, France.

Dr Sorin Pripon, Centre Hospitalier de Tarbes, Tarbes, France. Dr Tania Puscas, Hôpital Européen Georges Pompidou, Paris, France.

Dr Georges Sebanne, Hôpital Avicenne, AP-HP, Bobigny, France.

Dr Marie-France Seronde, CHU de Besançon, Besançon, France.

Dr Guillaume Taldir, Centre Hospitalier de Saint Brieuc, Saint-Brieuc, France.

Dr Jean-Michel Tartiere, Centre Hospitalier de Toulon, Toulon, France.

Prof. Achille Tchalla, Hôpital Dupuytren, CHU de Limoges, Limoges, France.

Dr Lory Trevisan, Centre Hospitalier Aix-en-Provence, Aix-en-Provence, France.

Prof. Jean-Noël Trochu, CHU de Nantes, Nantes, France. 